\title{
Inflammatory Subtypes in Classic Asthma and Cough Variant Asthma
}

This article was published in the following Dove Press journal:

Journal of Inflammation Research

\section{Jie Gao (i) \\ Feng Wu \\ Sifang Wu \\ Xing Yang}

Department of Pulmonary and Critical Care Medicine, Huizhou the Third People's Hospital, Guangzhou Medical College, Huizhou 516002, People's Republic of China
Correspondence: Sifang Wu; Xing Yang Huizhou the Third People's Hospital, Guangzhou Medical College, I\# Xuebei Ave., Huizhou, Guangdong, 516002,

China

Tel +86-13502436/32; +86-13528085770

Fax +86 752-2359648

Email wsf197906@I26.com;

87575589@qq.com
Background: Measurement of sputum is used to define airway inflammatory phenotypes. Cough variant asthma (CVA) is considered to be the initial stage of classic asthma (CA). The aim of this study was to describe the association between the different subtypes of CVA and CA. Methods: A total of 459 patients with CVA and CA were screened for the study. All included patients performed spirometry, underwent a bronchial challenge with methacholine and induced sputum according to the guidelines.

Results: A higher frequency of female patients were found with CVA and the eosinophilic airway inflammation of CVA than in CA and the noneosinophilic airway inflammation of CA ( $p=0.004$ and $p=0.024$, respectively). Bronchial hyper-responsiveness (BHR) was lower in eosinophilic CVA and CA $(p=0.006)$, while no difference was found in noneosinophilic CVA and CA. Association between the percentage of sputum eosinophils and the $\mathrm{FEV}_{1}$ level fell below $20 \%$ of the baseline value $\left(\mathrm{PD}_{20}\right)$ in CVA and $\mathrm{CA}(\mathrm{r}=-0.1245, p=0.0357$ and $\mathrm{r}=$ $-0.2148, p=0.0014$, respectively).

Conclusion: Eosinophilia may be associated with more severe disease, yet there was no difference in spirometry between the eosinophilic and noneosinophilic groups, and the BHR difference was not dramatic.

Keywords: cough variant asthma, airway inflammatory types, sputum induction, bronchial hyper-responsiveness

\section{Introduction}

Chronic cough is a very common condition, accounting for one third of patients to respiratory specialists in clinical practice, and significantly interferes with patients' daily life. ${ }^{1}$ According to the management guidelines of Classification of Cough as a Symptom in Adults and Management Algorithms, chronic cough has been defined as $>8$ weeks in duration for adults and adolescents $>14$ years old. ${ }^{2}$ In China, cough variant asthma (CVA) is the most common cause of chronic cough, accounting for more than $30 \%$ of the chronic cough. ${ }^{3}$ The original definition of CVA was described by Glauser in 1972, and later by McFadden in 1975, and Corrao et al in 1979.4-6 Patients with CVA were described with cough as their sole presenting symptom, and the symptom improved with bronchodilators alone. It should be noted this was only in patients in each study. ${ }^{6,7}$ The current literature described CVA as those with bronchial hyper-responsiveness (BHR), but with coughing to innocuous triggers such as talking, laughing, allergens, cold air. ${ }^{7,8}$ The American and European guidelines do not discuss specific diagnostic criteria, but they do highlight the diagnostic value of BHR and recommend that the CVA diagnosis should be determined according to the therapeutic response. ${ }^{9,10}$ The 2016 Chinese Diagnosis and 
Management of Cough guidelines take the basic diagnostic criteria: successful treatment of bronchodilators as the basic diagnostic of CVA. ${ }^{11}$ Based on the present of eosinophils in sputum, bronchoalveolar lavage (BAL) fluid and bronchial mucosal tissue, CVA is normally divided into eosinophilic and noneosinophilic airway inflammatory types, and whereas the eosinophilic type responds well to treatment of corticosteroids, noneosinophilic type shows little or no response. ${ }^{12,13}$ Studies on structural changes, such as subepithelial thickening, goblet cell hyperplasia, and vascular proliferation, show similarity between classic asthma (CA) and CVA. In addition, compared to CA, CVA shows a similar degree of eosinophilia in biopsy specimens of central airway mucosa and BAL fluid recovered from peripheral airways and parenchyma. ${ }^{14,15}$ However, most studies examined differences between CVA and $\mathrm{CA}$, while few investigations have been done to investigate differences in airway inflammatory types between CVA and CA. Therefore, the aim of this study was to assess (1) the difference in the degree of BHR and sputum cells between CVA and CA; (2) the difference in those biomarkers between different airway inflammatory types of CVA and/or CA; (3) the correlation between sputum cells and the degree of BHR between CVA and CA.

\section{Methods}

\section{Participants}

This retrospective observational study was conducted in Huizhou Third People's Hospital of Guangzhou Medical University between April 2017 and September 2019 in China. The primary diagnosis included history inquiring and physical examination, pulmonary function tests, induced sputum cell differentials and CT of the chest. The final diagnosis was made based on clinical manifestation, examination findings and a positive response to therapy, we enrolled a total of 459 patients with CVA and CA visiting the clinic.

CA patients $\geq 14$ years old were diagnosed according to (1) a clinical record of recurrent wheezing, dyspnea or/and cough episodes, chest tightness; (2) pulmonary function tests demonstrate variable airflow limitation by means of BHR testing or airway reversibility testing; (3) a positive to the therapeutic response, which satisfied the Chinese National Guidelines on Diagnosis and Management of Asthma (2016). ${ }^{16}$

CVA patients $\geq 14$ years old were diagnosed with (1) chronic cough (lasting more than eight weeks without specific cause) as the only symptom; (2) a cough that was usually dry or productive with minimal amounts of clear sputum, and was mainly nocturnal; (3) normal baseline lung function, some might actually include normal small airway function, and positive test for (direct) BHR; (4) no other cause of chronic cough; (5) a positive to the therapeutic response. ${ }^{11}$

Inclusion criteria were as follows: age greater than 14 years old; CA and CVA diagnosis was confirmed by medical chart review and the guideline criteria of China; ${ }^{11,16}$ all participants had confirmed asthma for at least three months, received initial diagnosis and were at uncontrolled stage; not taken any corticosteroid (ICS) in the previous four weeks; successfully performed pulmonary function test and sputum induction.

Exclusion criteria were as follows: a history of COPD or asthma-COPD overlap (ACO), bronchitis, bronchiectasis, lung cancer, cystic fibrosis or pneumonia; patients with upper airway cough syndrome (UACS), eosinophilic bronchitis (EB) and gastroesophageal reflux-related cough (GERC); ${ }^{11}$ discontinued treatment because of some reasons or diagnosed as other diseases after treatment.

\section{Ethics Statement}

The study was conducted in accordance with the Declaration of Helsinki, and the protocol was approved by the Ethics Committee of Huizhou Third People's Hospital, which absolved the need for written informed consent because of the retrospective study. All personal identification data were anonymized and de-identified before analysis.

\section{Study Procedures}

Pulmonary function tests, induced sputum cell differentials, and CT of the chest were performed on the same day. Clinical variables were recorded for the patients.

Variable airflow limitation was performed by lung function machine (MS-pneumo + APS; Jaeger; Germany). In accordance with recommendations of the Chinese National Guidelines of Pulmonary Function Test (2014): rapid rise in flow/volume curve, duration of expiration more than or equal to six seconds and visualization of peak expiratory flow (PEF) were required. Repeated at least three times (a reproducible way), the best spirometric values were measured prior to the methacholine challenge. Patient with a percent predicted forced expiratory volume in first second ( $\mathrm{FEV}_{1} \%$ pred) $\geq 60 \%$ continued to the BHR test (at baseline). The procedure 
was terminated when the $\mathrm{FEV}_{1}$ level fell below $20 \%$ of the baseline value. The positive response was defined as $\mathrm{PD}_{20}$ $\leq 2.504 \mu \mathrm{g}$ (between NS and $2.504 \mu \mathrm{g}$ ). ${ }^{17}$ The cumulative dose of $\mathrm{PD}_{20}$ was used to assess the degree of BHR. ${ }^{17,18}$

Sputum induction: patients were asked to inhale 200$400 \mu \mathrm{g}$ salbutamol via a metered dose inhaler and blow their nose and rinse their mouth before induction, and then sputum was induced by single $3 \%$ hypertonic saline inhalation through ultrasonic atomizer for $30 \mathrm{~min}$ in total. During inhalation, patients were encouraged to stop every $10 \mathrm{~min}$ to blow their nose and rinse their mouth, then cough deeply and expectorate sputum into a sterile container. The opaque and high-density part of sputum samples were collected and weighed immediately after expectoration. The selected samples were dispersed using $0.1 \%$ dithiothreitol in a volume equal to four times, and 60 $\mathrm{s}$ for the vortex. The mixed sputum suspension was placed in a water bath $\left(37^{\circ} \mathrm{C}\right)$ for $10 \mathrm{~min}$, during which period, one or two times to vortex to promote the cleavage. The suspension was filtered with 300 mesh nylon mesh filter to remove mucus and centrifuged at $3000 \mathrm{rpm}$ for $10 \mathrm{~min}$. Afterward, the resuspended cell pellet was smeared and stained with H\&E stain. The qualified sample was considered to squamous epithelial cell contamination $<10 \%$ and viable cells $>80 \%$. Differential cells count was obtained from 800 cells under $400 \times$ magnification to identify airway inflammation types by two skilled technicians. The variability of interobserver for cell counts was $<5 \%$ for neutrophils/macrophages and $<1 \%$ for eosinophils/lymphocytes. We defined sputum eosinophilia $\geq 2.5 \%$. ${ }^{11,19}$

\section{Statistical Analysis}

All the statistical variables were conducted with SPSS version 22 (IBM Corporation, Armonk, NY, USA). The data were presented as the mean $\pm \mathrm{SD}$. The statistical comparisons were analyzed by the Student's $t$-test and the chi-squared test between two groups, and the Pearson correlation coefficient tests were performed with the relationship between $\mathrm{PD}_{20}$ and sputum cells. $p$-values $<0.05$ were considered statistically significant.

\section{Results}

A total of 459 patients with CVA $(n=241)$ and CA $(n=218)$ were included in the study. All participants were Chinese. Characteristics of the two group patients are summarized in Table 1. Significant differences were found in the female to male ratio, smoker ratio, duration of disease, spirometry, $\mathrm{PD}_{20}$ and the percent of sputum cells. Females were the most frequent in CVA $(66.81 \%, p=0.004)$. More smokers and longer duration of disease were shown in CA ( $p=0.023$ and $p<0.001$, respectively). According to the results of spirometry and bronchial challenge test, $\mathrm{FEV}_{1} \%$ predicted, $\mathrm{FEV}_{1} / \mathrm{FVC}, \mathrm{PEF} \%$ predicted and small airways (MMEF\% predicted, $\mathrm{FEF}_{50} \%$ predicted and $\mathrm{FEF}_{75 \%}$ predicted) were higher in CVA compared to CA $(p<0.05)$, as well as the $\operatorname{PD}_{20}(p=0.016)$.

The results of induced sputum are presented in Table 2. Eosinophils proportion in induced sputum was lower in CVA, whereas patients in CA was lower in proportion of neutrophils. The proportion of lymphocyte and macrophagocytes was similar to CVA and CA patients.

According the recommendations of China, sputum eosinophilia was defined as $\geq 2.5 \%$. Patients with CVA or CA were divided into the eosinophilic airway inflammatory type group and the non eosinophilic airway inflammatory type group. In the eosinophilic airway inflammatory of CVA or CA, patients had lower $\mathrm{PD}_{20}$ and proportion of neutrophils compare to the diseases of non eosinophilic airway inflammatory type $(p \leq 0.01)$. Small airways $\left(\mathrm{MMEF} \%\right.$ predicted, $\mathrm{FEF}_{50 \%}$ predicted and $\mathrm{FEF}_{75 \%}$ predicted) were higher in the noneosinophilic airway inflammatory of CA $(p<0.05)$, which were similar in different airway inflammatory types of CVA (Table 3).

Patients with the eosinophilic airway inflammation of CVA had shorter duration of disease, more females, higher spirometry, and also $\mathrm{PD}_{20}$, proportion of neutrophils, compared to patients with the eosinophilic airway inflammation of CA $(p<0.05)$. Fewer smokers and shorter duration of disease in patients with the noneosinophilic airway inflammation of CVA compared to patients with the noneosinophilic airway inflammation of CA $(p<0.05)$. Proportion of sputum eosinophils were lower in CVA both in eosinophilic airway inflammation of CVA and CV and in noneosinophilic airway inflammation of CVA and CA (Table 3).

Relationships between the percentage of sputum eosinophils and $\mathrm{PD}_{20}, \mathrm{FEV}_{1} \%$ were also analyzed in the study. Significant association between the percentage of sputum eosinophils and $\mathrm{PD}_{20}$ in CVA and CA $(\mathrm{r}=-0.1245$, $p=0.0357$ and $\mathrm{r}=-0.2148, p=0.0014$, respectively) (Figure $1 \mathrm{~A}$ and $\mathrm{C})$. A collection between the percentage of sputum eosinophils and $\mathrm{FEV}_{1} \%$ was also found in $\mathrm{CA}(\mathrm{r}=-0.1594$, $p=0.0185$ ) (Figure 1B), whereas no significant in CVA. There were no relationships between the percentage of sputum neutrophils and $\mathrm{PD}_{20}, \mathrm{FEV}_{1} \%(p>0.05)$. 
Table I Demographics, Duration of Disease and Spirometry of Included Patients

\begin{tabular}{|c|c|c|c|}
\hline Parameter & CA $(n=2 \mid 8)$ & CVA $(n=24 I)$ & $p$ \\
\hline Age, years & $45.76 \pm 15.88$ & $46.01 \pm 16.16$ & 0.869 \\
\hline Females, n (\%) & I I 7 (53.67\%) & $16 \mid(66.81 \%)$ & 0.004 \\
\hline Smokers, n (\%) & $92(44.2 \%)$ & 77 (3I.05\%) & 0.023 \\
\hline Duration of disease (months) & $45.69 \pm 89.12$ & $20.97 \pm 50.51$ & $<0.001$ \\
\hline BMI, $\mathrm{kg} / \mathrm{m}^{2}$ & $23.09 \pm 4.77$ & $23.93 \pm 5.09$ & 0.096 \\
\hline $\mathrm{FVC}(\mathrm{L})$ & $3.23 \pm 0.83$ & $3.12 \pm 0.81$ & 0.171 \\
\hline FVC\% predicted & $96.87 \pm 12.56$ & $98.02 \pm 13.34$ & 0.343 \\
\hline $\mathrm{FEV}_{\mathrm{I}}(\mathrm{L})$ & $2.34 \pm 0.62$ & $2.38 \pm 0.66$ & 0.547 \\
\hline $\mathrm{FEV}, \%$ predicted & $84.62 \pm 11.44$ & $89 \pm 12.69$ & $<0.001$ \\
\hline $\mathrm{FEV}_{\mathrm{I}} / \mathrm{FVC}(\%)$ & $72.5 \pm 9.42$ & $75.87 \pm 8.18$ & $<0.001$ \\
\hline PEF (L/min) & $6.05 \pm 1.68$ & $6.13 \pm 1.73$ & 0.64 \\
\hline PEF\% predicted & $86.21 \pm 6.28$ & $89.8 I \pm 5.66$ & 0.016 \\
\hline MMEF (L/sec) & $\mathrm{I} .74 \pm 0.84$ & $1.95 \pm 0.88$ & 0.009 \\
\hline MMEF\% predicted & $47.87 \pm 18.25$ & $54.54 \pm 18.60$ & $<0.001$ \\
\hline $\mathrm{FEF}_{50}(\mathrm{~L} / \mathrm{sec})$ & $2.16 \pm 0.9$ & $2.4 I \pm 0.98$ & 0.004 \\
\hline $\mathrm{FEF}_{50} \%$ predicted & $52.12 \pm 19.19$ & $58.48 \pm 19.8$ & 0.001 \\
\hline $\mathrm{FEF}_{75}(\mathrm{~L} / \mathrm{sec})$ & $0.76 \pm 0.47$ & $0.88 \pm 0.49$ & 0.007 \\
\hline $\mathrm{FEF}_{75} \%$ predicted & $43.57 \pm 20.45$ & $50.6 \pm 20.7$ & $<0.001$ \\
\hline $\mathrm{PD}_{20}(\mu \mathrm{g})$ & $0.63 \pm 0.76$ & $0.76 \pm 0.79$ & 0.016 \\
\hline 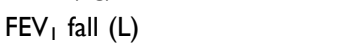 & $1.61 \pm 0.53$ & $|.72 \pm 0.5|$ & 0.019 \\
\hline FEV , fall (\%) & $31.38 \pm|2.6|$ & $27.55 \pm 6.95$ & $<0.001$ \\
\hline
\end{tabular}

Notes: Data are expressed as the mean \pm SD or frequencies; the difference between groups was analyzed by Student's $t$-test or chi squared. $p<0.05$ vs the control. Abbreviations: $n$, sub-group population; PEF, peak expiratory flow; MMEF, maximum mid-expiratory flow; $F E F$, forced expiratory flow; $\mathrm{PD}_{20}$, fall of $\mathrm{FEV}$, by $20 \%$ of prechallenge value.

Table 2 The Proportion of Induced Sputum Cells in Included Patients

\begin{tabular}{|l|l|l|l|}
\hline Parameter & CA (n=2 18) & CVA (n=24I) & $\mathbf{P}$ \\
\hline Eosinophils, \%, mean (SD) & $13.57 \pm 19.76$ & $9.32 \pm 14.37$ & 0.009 \\
Neutrophils, \% & $69.25 \pm 22.89$ & $74.69 \pm 20.45$ & 0.008 \\
Lymphocytes, \% & $1 \pm 1.31$ & $1.49 \pm 5.24$ & $0.17 \mid$ \\
Macrophagocytes,\% & $16.16 \pm 15.52$ & $14.56 \pm \mid 4.75$ & 0.261 \\
\hline
\end{tabular}

Notes: Data are expressed as the mean $\pm S D$; the difference between groups was analyzed by Student's $t$-test. $p<0.05$ vs the control.

\section{Discussion}

The present study, which assessed the clinical characteristics in different inflammatory types between CVA and CA, showed that more patients with CVA and the eosinophilic airway inflammation of CVA were associated with significant differences in levels of sex, smoker, duration of disease, spirometry, BHR and proportion of sputum cells, compared to patients with $\mathrm{CA}$ and the noneosinophilic CVA, respectively. The eosinophilic airway inflammation of CVA and CA showed severer BHR, and had lower in the percentage of sputum neutrophils compared to the noneosinophilic airway inflammation of CVA and CA, respectively. The percentage of sputum eosinophils correlated with BHR in CVA and CA, but weak. $\mathrm{FEV}_{1} \%$ had a relationship with proportion of eosinophils in CA.

Chronic cough is the sole presenting symptom of CVA. Previous literatures have studied that chronic persistent nonproductive cough is more frequent in females, and females are more easily troubled by the symptom. ${ }^{20,21}$ Females exceed males in number among patients attending specialist respiratory clinics. ${ }^{22}$ The cough threshold is lower in females than in males, illustrating that the cough sensitivity is heightened in females. ${ }^{22,23}$ In our study, the difference of gender is obvious. The number of females was more frequent in CVA and the eosinophilic airway inflammation of CVA than in CA and the noneosinophilic airway inflammation of CA $(p=0.004$ and $p=0.024$, respectively). The mechanism of the gender differences is still unclear, and additional studies are needed to better understand gender differences.

Cigarette smoking is a risk factoring for cough. ${ }^{24}$ Regular smokers have a much higher prevalence of chronic cough than never smokers and ex-smokers. ${ }^{24,25}$ The number of smokers in CVA was less compared to CA $(p=0.023)$. Smokers were higher in the noneosinophilic CA compared to the noneosinophilic CVA $(p=0.018)$, 
Table 3 Demographics, Durationof Disease, Spirometry and Induced Sputum Features of CVA and CA

\begin{tabular}{|c|c|c|c|c|c|c|c|c|}
\hline & \multirow{2}{*}{$\begin{array}{l}\text { CA-Sputum } \\
\text { Eosinophilia }\end{array}$} & \multirow{2}{*}{$\begin{array}{l}\text { CA-Sputum } \\
\text { Noneosinophilia }\end{array}$} & \multirow{2}{*}{$\begin{array}{l}\text { CVA- } \\
\text { Sputum } \\
\text { Eosinophilia }\end{array}$} & \multirow{2}{*}{$\begin{array}{l}\text { CVA-Sputum } \\
\text { Noneosinophilia }\end{array}$} & \multicolumn{4}{|c|}{$p$-values } \\
\hline & & & & & $\begin{array}{l}\text { CA-SE } \\
\text { vs CA- } \\
\text { NSE }\end{array}$ & $\begin{array}{l}\text { CVA-SE } \\
\text { vs CVA- } \\
\text { NSE }\end{array}$ & $\begin{array}{l}\text { CA-SE } \\
\text { vs } \\
\text { CVA- } \\
\text { SE }\end{array}$ & $\begin{array}{l}\text { CA-SNE } \\
\text { vs CVA- } \\
\text { SNE }\end{array}$ \\
\hline $\mathrm{n}$ & 132 & 86 & 126 & 115 & & & & \\
\hline $\begin{array}{l}\text { Durationof disease } \\
\text { (months) }\end{array}$ & $48.02 \pm 96.47$ & $42.13 \pm 76.89$ & $25.23 \pm 58.58$ & $16.3 \pm 39.59$ & 0.618 & 0.171 & 0.021 & 0.005 \\
\hline Age, years & $45.03 \pm 15.26$ & $46.88 \pm \mid 6.81$ & $43.51 \pm 16.12$ & $48.75 \pm|5.8|$ & $0.4 I I$ & 0.012 & 0.437 & 0.426 \\
\hline Females, n (\%) & $66(50)$ & $51(59.3)$ & 81 (64.29) & $80(69.57)$ & 0.156 & 0.385 & 0.024 & 0.131 \\
\hline BMI, $\mathrm{kg} / \mathrm{m}^{2}$ & $23.32 \pm 3.39$ & $23.47 \pm 3.52$ & $22.83 \pm 3.41$ & $23.76 \pm 3.82$ & 0.749 & 0.084 & 0.249 & 0.809 \\
\hline Smokers, n (\%) & $56(42.42)$ & $36(4 I .86)$ & $47(37.3)$ & $30(26.09)$ & 0.878 & 0.062 & 0.373 & 0.018 \\
\hline FVC\% predicted & $96.85 \pm 12.6$ & $96.9 \pm 12.57$ & $97.99 \pm 13.4$ & $98.05 \pm 13.33$ & 0.977 & 0.973 & 0.482 & 0.535 \\
\hline $\mathrm{FEV}_{1}(\mathrm{~L})$ & $2.36 \pm 0.64$ & $2.3 I \pm 0.6$ & $2.47 \pm 0.65$ & $2.28 \pm 0.67$ & 0.601 & 0.052 & 0.172 & 0.685 \\
\hline $\mathrm{FEV}, \%$ predicted & $83.47 \pm 12.2$ & $86.39 \pm 9.97$ & $88.08 \pm 12.85$ & $90 \pm 12.5$ & 0.066 & 0.239 & 0.001 & 0.025 \\
\hline $\mathrm{FEV}_{1} / \mathrm{FVC}(\%)$ & $71.44 \pm 8.89$ & $74.12 \pm 10$ & $75.35 \pm 8.7$ & $76.44 \pm 7.58$ & 0.4 & 0.302 & $<0.001$ & 0.074 \\
\hline PEF\% predicted & $85.56 \pm 16.39$ & $87.17 \pm 16.15$ & $90.88 \pm 14.75$ & $88.62 \pm 15.59$ & 0.477 & 0.264 & 0.007 & 0.537 \\
\hline MMEF\% predicted & $45.75 \pm 17.49$ & $51.14 \pm 19$ & $54.11 \pm 19.83$ & $55 \pm 17.22$ & 0.036 & 0.71 & $<0.001$ & 0.133 \\
\hline $\mathrm{FEF}_{50 \%}$ predicted & $49.94 \pm 18.6$ & $55.46 \pm 19.7$ & $58.08 \pm 20.12$ & $58.91 \pm 19.52$ & 0.038 & 0.748 & 0.001 & 0.22 \\
\hline $\mathrm{FEF}_{75 \%}$ predicted & $40.95 \pm|9.5|$ & $47.58 \pm 2|3|$ & $50.92 \pm 21.73$ & $50.25 \pm 19.6$ & 0.019 & 0.803 & $<0.001$ & 0.359 \\
\hline $\mathrm{PD}_{20}(\mu \mathrm{g})$ & $0.46 \pm 0.66$ & $0.9 \pm 0.83$ & $0.6 \pm 0.72$ & $0.93 \pm 0.82$ & $<0.001$ & 0.001 & 0.006 & 0.802 \\
\hline Eosinophils, \% & $21.84 \pm 21.72$ & $0.88 \pm 0.77$ & $17.22 \pm 16.26$ & $0.67 \pm 0.72$ & - & - & 0.035 & 0.023 \\
\hline Neutrophils, \% & $61.38 \pm 23.16$ & $81.33 \pm 16.33$ & $66.63 \pm 21.54$ & $83.5 I \pm 14.89$ & $<0.001$ & $<0.001$ & 0.016 & 0.332 \\
\hline Lymphocytes, \% & $0.93 \pm 1.52$ & $1.13 \pm 1.53$ & $1.09 \pm 1.61$ & $1.93 \pm 7.39$ & 0.280 & 0.236 & 0.956 & 0.777 \\
\hline Macrophagocytes, \% & $15.83 \pm \mid 4.84$ & $16.66 \pm 16.59$ & $14.64 \pm 14.49$ & $|4.4| 5.09$ & 0.699 & 0.935 & 0.405 & 0.369 \\
\hline
\end{tabular}

Notes: Data are expressed as the mean \pm SD or frequencies; the difference between groups was analyzed by Student's $t$-test or chi-squared. $p<0.05$ vs the control. Abbreviations: $n$, sub-group population; PEF, peak expiratory flow; MMEF, maximum mid-expiratory flow; FEF, forced expiratory flow; $P D_{20}$, fall of $F E V_{1}$ by $20 \%$ of prechallenge value; CA-SE: CA-sputum eosinophilia; CA-SNE: CA-sputum non-eosinophilia; CVA-SE: CVA-sputum eosinophilia; CVA-SNE: CVA-sputum non-eosinophilia.

whereas smokers showed no difference between the eosinophilic CVA and the eosinophilic CA $(p=0.373)$ in our study. Broekema et al suggested that smoking in asthma caused higher neutrophils and lower eosinophils in sputum than nonsmokers. ${ }^{26}$ This was not consistent with our study, probably due to the proportion of females and duration disease.

Spirometry and BHR are the basic diagnostic criteria of CVA or CA according to the guidelines. ${ }^{10,16,17}$ The degree of BHR is most likely associated with airway inflammatory types, number and activity of inflammatory cells, damage and malfunction of epithelial cells and abnormal neural control. It is defined as position of the dose-response curve during bronchial challenge. ${ }^{10,17}$ Spirometry and degree of BHR showed milder in CVA compared to CA $(p=0.016)$ similar with the present study. ${ }^{15}$ Our study found that BHR was higher in patients with eosinophilic CVA and CA than in those with noneosinophilic CVA and CA, as well as being much higher in eosinophilic CVA compared to eosinophilic CA. These suggested that while eosinophil was associated with an increased degree of BHR, this was not the case in neutrophilia, nor was neutrophilia associated with significantly lower BHR. The results were consistent with the study of Porsbjerg et al. ${ }^{27}$

Eosinophilic airway inflammatory subtype is a fundamental feature of asthma. More recently, inflammatory subtypes of asthma have been proposed as defined by proportion of sputum cell. ${ }^{10,16}$ Subjects with "eosinophilic asthma" defined as sputum eosinophils $\geq 2.5 \%$ and "noneosinophilic asthma" as noneosinophils $<2.5 \%$, were in our study. ${ }^{16}$ The percentage of sputum eosinophils showed less in CVA, eosinophilic CVA and noneosinophilic CVA compared to CA, eosinophilic CA and noneosinophilic CA $(p=0.009, p=0.035$ and $p=0.023$, respectively). The percentage of sputum eosinophils was associated with an increased degree of BHR in CVA and CA ( $\mathrm{r}=-0.1245, p=0.0357$ and $\mathrm{r}=-0.2148$, $p=0.0014$, respectively). Results of previous studies indicated that increasing BHR has a pathogenetic role in development of wheezing during the course of CVA. ${ }^{12}$ 

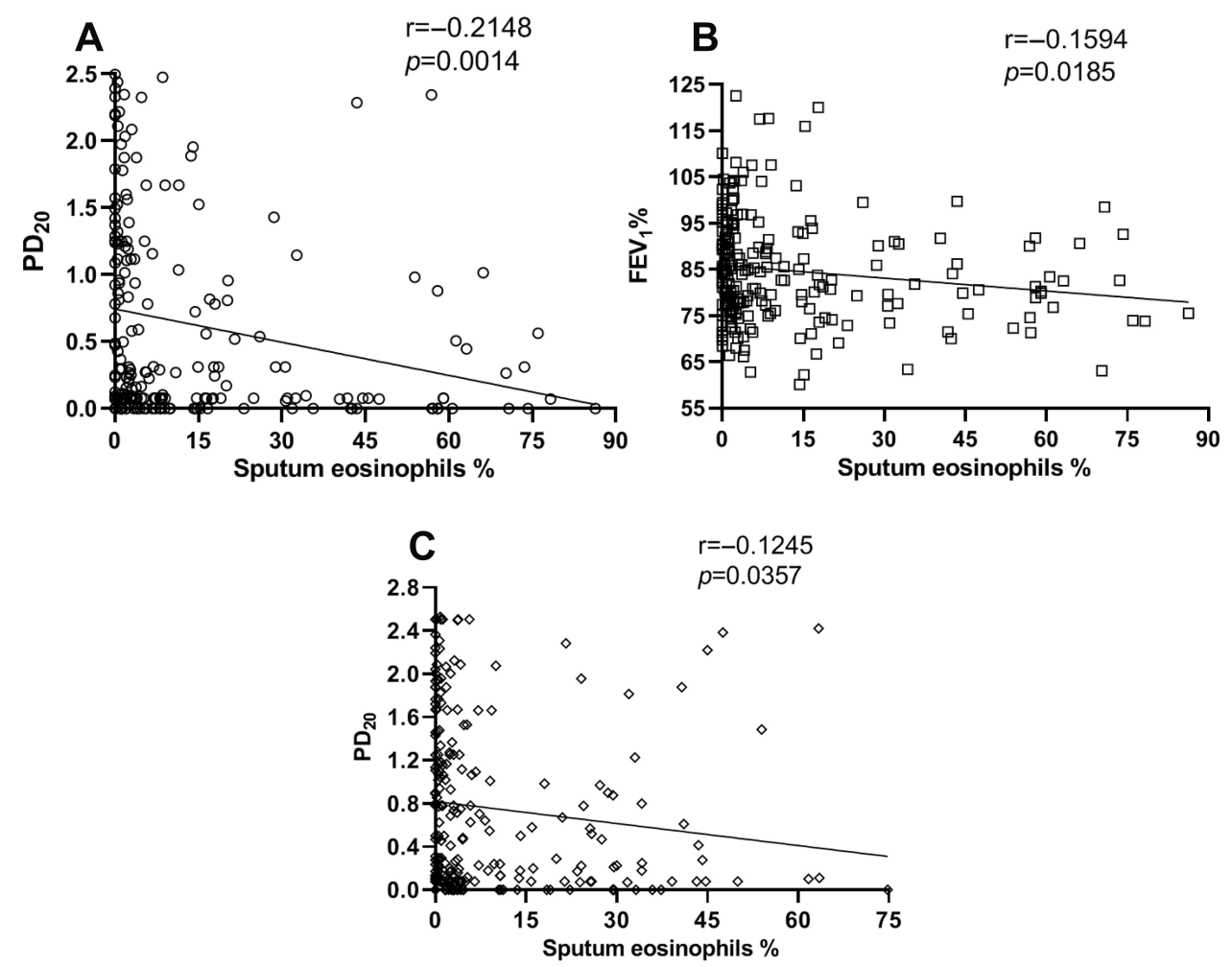

Figure I Scatter plots of correlation between the percentage of sputum eosinophils and $\mathrm{PD}_{20}(\mu \mathrm{g})$, FEV 1 . (A) Correlation between the percentage of sputum eosinophils and $\mathrm{PD}_{20}$ in CA. (B) Correlation between the percentage of sputum eosinophils and $F E V_{1} \%$ in CA. (C) Correlation between the percentage of sputum eosinophils and PD 20 in $C V A$.

Classic asthma is likely to develop in $30 \%$ of CVA. These suggested that the level of sputum eosinophils in CVA is a risk factor for the future development of CA.

A limitation of our study does not distinguish in atopic or nonatopic patients with CVA and CA. Furthermore, the patients represent a selected group, and the results may not readily be extrapolated to a more general population of asthma patients, but need to be repeated in a random population sample.

\section{Conclusions}

Our findings have shown that patients with CVA and CV have differences of response to demographics, bronchial challenge and sputum eosinophil and neutrophil proportions, which likely reflects different airway inflammatory subtypes. Sputum eosinophils are involved in the pathophysiology of CVA, as well as sputum neutrophils. Eosinophilia may be associated with more severe disease, yet there was no difference in spirometry between the eosinophilic and noneosinophilic groups, and the BHR difference was not dramatic. However, more different pathophysiological mechanisms in CVA and CA are required to future prospective studies.

\section{Disclosure}

The authors report no conflicts of interest in this work.

\section{References}

1. Yang CZ, Chen RC, Li BK, et al. Survey of quality of life and incontinence in female patients with chronic cough. Chin J Asthma. 2010;4:199-202.

2. Irwin RS, French CL, Chang AB, et al. Classification of cough as a symptom in adults and management algorithms: CHEST guideline and expert panel report. Chest. 2018;153:196-209.

3. Lai K, Chen R, Lin J, et al. A prospective, multicenter survey on causes of chronic cough in China. Chest. 2013;143:613-620.

4. Glauser FL. Variant asthma. Ann Allergy. 1972;30:457-459.

5. McFadden ER Jr. Exertional dyspnea and cough as preludes to acute attacks of bronchial asthma. N Engl JMed. 1975;292:555-559.

6. Corrao WM, Braman SS, Irwin RS. Chronic cough as the sole presenting manifestation of bronchial asthma. $N$ Engl $J$ Med. 1979;300:633-637.

7. Matsumoto H, Niimi A, Takemura M, et al. Features of cough variant asthma and classic asthma during methacholine-induced bronchoconstriction: A cross-sectional study. Cough. 2009;5:3.

8. De Diego A, Martínez E, Perpiñá M, et al. Airway inflammation and cough sensitivity in cough-variant asthma. Allergy. 2005;60:1407-1411.

9. French CT, Diekemper RL, Irwin RS, et al. Assessment of intervention fidelity and recommendations for researchers conducting studies on the diagnosis and treatment of chronic cough in the adult: CHEST Guideline and Expert Panel Report. Chest. 2015;148:32-54.

10. Global Initiative for Asthma. Global strategy for asthma managementand prevention. Available from: http://ginasthma.org/2019pocket-guide-for-asthmamanagement-andprevention/. Accessed 19 2019. 
11. Asthma Workgroup of Chinese Society of Respiratory Diseases (CSRD), Chinese Medical Association. The Chinese national guidelines on diagnosis and management of cough (2015). Chin J Tuberc Respir Dis. 2016;39:321-339.

12. Niimi A, Amitani R, Suzuki K, et al. Eosinophilic inflammation in cough variant asthma. Eur Respir J. 1998;11:1064-1069.

13. Gibson PG, Fujimura M, Niimi A. Eosinophilic bronchitis: clinical manifestations and implications for treatment. Thorax. 2002;57:178182.

14. Niimi A, Matsumoto H, Minakuchi M, et al. Airway remodelling in cough-variant asthma. Lancet. 2000;356:564-565.

15. Niimi A, Torrego A, Nicholson AG, et al. Nature of airway inflammation and remodeling in chronic cough. $J$ Allergy Clin Immunol. 2005;116:565-570.

16. Asthma Workgroup of Chinese Society of Respiratory Diseases (CSRD), Chinese Medical Association. The Chinese national guidelines on diagnosis and management of asthma (2016). Chin J Tuberc Respir Dis. 2016;39:675-697.

17. Pulmonary Function Workgroup of Chinese Society of Respiratory Diseases (CSRD), Chinese Medical Association. The Chinese national guidelines of pulmonary function test (2014). China. $J$ Tuberc Respir Dis. 2014;37:566-571.

18. Miller MR, Hankinson J, Brusasco V, et al. ATS/ERS Task Force Standardization of spirometry. Eur Respir J. 2005;26:319-338.

19. Luo W, Chen Q, Chen R, et al. Reference value of induced sputum cell counts and its relationship with age in healthy adults in Guangzhou: southern China. Clin Respir J. 2018;12:11601165 .
20. Fujimura M, Sakamoto S, Matsuda T. Bronchodilator-resistive cough in atopic patients: bronchial reversibility and hyperresponsiveness. Intern Med. 1992;31:447-452.

21. Fujimura M, Kamio Y, Hashimoto T, et al. Cough receptor sensitivity and bronchial responsiveness in patients with only chronic nonproductive cough in view of effect of bronchodilator therapy. J Asthma. 1994;31:463-472.

22. Irwin RS, Boulet LP, Cloutier MM, et al. Managing cough as a defense mechanism and as a symptom: a consensus panel report of the American College of Chest Physicians. Chest. 1998;114:133S-81S.

23. Fujimura M, Kasahara K, Kamio Y, et al. Female gender as a determinant of cough threshold to inhaled capsaicin. Eur Respir J. 1996;9:1624-1626.

24. Zemp E, Elsasser S, Schindler C, et al. Long-term ambient air pollution and respiratory symptoms in adults (SAPALDIA study). Am J Respir Crit Care Med. 1999;159:1257-1266.

25. Barbee RA, Halonen M, Kaltenborn WT, et al. A longitudinal study of respiratory symptoms in a community population sample. Correlations with smoking, allergen skin-test reactivity, and serum IgE. Chest. 1991;99:20-26.

26. Broekema M, Ten Hacken NH, Volbeda F, et al. Airway epithelial changes in smokers but not in ex-smokers with asthma. Am J Respir Crit Care Med. 2009;180:1170-1178.

27. Porsbjerg C, Lund TK, Pedersen L, et al. Inflammatory subtypes in asthma are related to airway hyperresponsiveness to mannitol and exhaled NO. J Asthma. 2009;46:606-612.
Journal of Inflammation Research

\section{Publish your work in this journal}

The Journal of Inflammation Research is an international, peerreviewed open-access journal that welcomes laboratory and clinical findings on the molecular basis, cell biology and pharmacology of inflammation including original research, reviews, symposium reports, hypothesis formation and commentaries on: acute/chronic inflammation; mediators of inflammation; cellular processes; molecular mechanisms; pharmacology and novel anti-inflammatory drugs; clinical conditions involving inflammation. The manuscript management system is completely online and includes a very quick and fair peerreview system. Visit http://www.dovepress.com/testimonials.php to read real quotes from published authors. 